\title{
Carga Tributária e Gasto Público: Propaganda e Terceirização*
}

\section{HUGO DE BRITO MACHADO}

Juiz aposentado do TRF da 5a Região. Professor Titular de Direito Tributário da UFC. Presidente do Instituto Cearense de Estudos Tributários.

www.hugomachado.adv.br

Sumário: 1) Introdução; 2) Propaganda governamental; 3) Terceirização nos serviços públicos; 4) Considerações finais.

Palavras-chave: Tributos. Estado. Propaganda. Terceirização.

\section{@) INTRODUÇÃO}

A questão da elevada carga tributária tem ocupado significativos espaços nos meios de divulgação de massa e mais de uma vez observou-se certa reação da sociedade contra a pretensão de aumento de tributo. Tornam-se, aliás, freqüentes as manifestações neste sentido, apontando a necessidade de se dar um basta às pretensões do governo de criar novos tributos ou elevar os existentes. Reação que se justifica especialmente em face da elevação de nossa carga tributária nos últimos anos.

Os governos sempre encontram argumentos para instituir tributos. Geralmente de cunho demagógico, de forte apelo ao sentimento das pessoas, que terminam comovidas e se submetem às novas exigências. Quando o Presidente João Figueiredo comemorava a instituição do FINSOCIAL, com alíquota de 0,5\% (meio por cento) incidente sobre o faturamento das empresas, disse emocionado, chorando, que agora a pobreza seria erradicada de nosso País. Muitos anos se passaram. O tributo sobre o faturamento mudou de nome e teve sua alíquota

\footnotetext{
* Palestra proferida na FA7 em 27. out. 06.
} 
elevada várias vezes, sendo hoje de 7,6\%, e mesmo assim a população pobre cresceu de forma significativa.

Recentemente tivemos a instituição do denominado Fundo de Combate à Pobreza, com Emenda Constitucional que permitiu aos Estados o aumento da alíquota do ICMS incidente sobre produtos supérfluos. Foram elevadas as alíquotas desse imposto, para combustíveis e energia elétrica, que na verdade não são supérfluos. O óleo diesel, aliás, é subsidiado pelo governo, o que é bastante para afastar dele essa qualificação. Mas ao governo não importa coerência. Nem importa o Direito. Imposta simplesmente arrecadar.

Ocorre que nossa capacidade contributiva está esgotada. Nem se venha argumentar com a possibilidade de aumento da receita decorrente do combate à sonegação, sem aumento das alíquotas dos impostos já existentes. A sonegação já é uma conseqüência das alíquotas exageradamente elevadas e da multiplicidade de incidências tributárias sobre os mesmos fatos. A solução adequada reside mesmo na redução nominal dos tributos, com a qual até se pode esperar um aumento da receita, embora não se possa assegurar que isto vai ocorrer.

Seja como for, se admitirmos que o gasto dos valores atualmente despendidos é necessário, que não é possível a redução desses gastos, é inútil pensarmos em redução da carga tributária. É preciso, portanto, encontrarmos uma forma de reduzir os gastos públicos. E isto é perfeitamente possível. Um exame criterioso dos orçamentos dos diversos órgãos públicos com certeza nos mostrará vários pontos nos quais é possível redução de gastos. Basta que exista vontade política para tanto. Mesmo sem tal exame, porém, podemos indicar desde logo dois pontos nos quais é possível a redução do gasto e o ordenamento jurídico já nos permite trabalhar nesse sentido, embora seja recomendável a mudança das leis para tornar esse trabalho mais fácil e rápido. Esses dois pontos são a propaganda governamental e a terceirização nos serviços públicos, como vamos demonstrar.

\section{- Propaganda Governamental}

\subsection{Desnecessidade do Gasto}

Quando se questiona qualquer redução de gastos a primeira questão que se coloca é a de saber se eles são necessários, ou não. Resolvida essa questão afirmativamente, vale dizer, depois que se chega à conclusão de que um gasto é necessário é que se coloca a questão das prioridades. Quais são os gastos mais necessários. Qual a prioridade. E quando se chega à conclusão de que o gasto é desnecessário a questão está resolvida. Deve ser evitado.

No caso dos gastos com propaganda, com certeza nem será ultrapassada a primeira questão, pois tais gastos são na verdade inteiramente desnecessários. Na empresa privada a propaganda é necessária para atrair clientela. Daí a divulgação 
insistente das qualidades de muitos produtos e serviços. É a disputa do mercado. A disputa do cliente porque este gera a receita sem a qual a empresa não pode sobreviver. Os órgãos do Estado não precisam fazer propaganda. Seus serviços, embora geralmente sejam de má qualidade, não são suficientes para atender aqueles que os procuram. Nenhuma entidade prestadora de serviços públicos precisa atrair clientes. Eles já existem, e muitos, em filas intermináveis porque a capacidade de atendimento é geralmente insuficiente.

A propaganda governamental na verdade é feita para a promoção pessoal dos governantes, tanto que no passado veiculava seus nomes e fotografias. Já não pode fazê-lo mas veicula, ainda que indevidamente, mensagens que de algum modo, ainda que apenas em razão de circunstâncias, identificam os favorecidos com a divulgação.

\subsection{Inconstitucionalidade do Gasto com Propaganda}

Não se venha invocar o disposto no art. $37, \S 1^{\circ}$, da vigente Constituição Federal, para sustentar que a mesma autoriza a propaganda governamental. O referido dispositivo na verdade a proíbe, embora essa proibição venha sendo ignorada a toda hora.

Realmente, o referido dispositivo estabelece:

"A publicidade dos atos, programas, obras, serviços, e campanhas dos órgãos públicos deverá ter caráter educativo, informativo ou de orientação social, dela não podendo constar nomes, símbolos ou imagens que caracterizem promoção pessoal de autoridades ou servidores públicos.”

Como se vê, proíbe expressamente a propaganda governamental. Autoriza a publicidade, mas proíbe que da mesma constem nomes, símbolos ou imagens que caracterizem promoção pessoal de autoridades ou servidores públicos.

Para compreendermos a proibição em tela basta que tenhamos presente a distinção entre publicidade e propaganda. A palavra publicidade tem sentido amplo que envolve a idéia de propaganda, mas é indiscutível que esta alberga um sentido específico que a distingue. A propaganda é uma espécie de publicidade, que se caracteriza pela finalidade de influir nas pessoas às quais é dirigida.

Nos órgãos públicos, exatamente porque são públicos, todos os atos praticados devem ser transparentes. Neles deve ser adotada a publicidade como um princípio. A esse respeito doutrina Celso Antônio, com inteira propriedade: 
"Deveras, se os interesses públicos são indisponíveis, se são interesses de toda a coletividade, os atos emitidos a título de implementá-los hão de ser exibidos em público. O princípio da publicidade impõe transparência na atividade administrativa exatamente para que os administrados possam conferir se está sendo bem ou mal conduzida." ${ }^{1}$

Ainda a respeito do princípio da publicidade, referindo-se aos dispositivos constitucionais que o consagram, doutrina Celso Antônio com inteira propriedade:

“Não pode haver em um Estado Democrático de Direito, no qual o poder reside no povo (art. $1^{\circ}$, parágrafo único, da Constituição), ocultamento aos administrados dos assuntos que a todos interessam, e muito menos em relação aos sujeitos individualmente afetados por alguma medida.

Tal princípio está previsto expressamente no art. 37, caput, da Lei Magna, ademais de contemplado em manifestações específicas do direito à informação sobre os assuntos públicos, quer pelo cidadão, pelo só fato de sê-lo, quer por alguém que seja pessoalmente interessado. É o que se lê no art. $5^{\circ}$, XXXIII (direito à informação) e XXXIV, “b”, este último para o caso específico de certidão (a ser expedida no prazo máximo de 15 dias, conforme a Lei 9.051, de 18.5.95) para defesa de direitos e esclarecimento de situações de interesse pessoal. Além disso, o mesmo art. 5, no inciso LXXII, confere a garantia do hábeas data para assegurar judicialmente o conhecimento de informações relativas ao impetrante que constem de registros ou bancos de dados de entidades governamentais ou de âmbito público, bem como para retificação de dados que neles estejam armazenados.”2

A publicidade dos atos do Estado é uma garantia do cidadão. Como então se explica seja proibida a propaganda governamental?

A resposta pode ser facilmente encontrada no dispositivo constitucional acima transcrito. Nele está dito expressamente que a publicidade por ele autorizada deverá ter caráter educativo, informativo ou de orientação social. Está definida, pois, a finalidade. Esta só pode ser educativa, informativa e de orientação social. Não

${ }^{1}$ Celso Antônio Bandeira de Mello. Curso de Direito Administrativo, 18 ${ }^{a}$ edição, Malheiros, São Paulo, 2005, pág. 75.

2 Celso Antônio Bandeira de Mello. Curso de Direito Administrativo, 18 edição, Malheiros, São Paulo, 2005, pág. 104/105. 
qualquer outra. E ao proibir que dessa publicidade constem nomes, símbolos ou imagens que caracterizem promoção pessoal de autoridades ou servidores públicos, o dispositivo proíbe expressamente a propaganda, que restaria caracterizada pela finalidade de promoção pessoal da autoridade ou do servidor público.

Indiscutível, portanto, a proibição de propaganda governamental que tem a exclusiva finalidade de promover a autoridade ou o servidor público, embora não veicule seu nome nem seu retrato. Basta que veicule símbolos ou imagens que caracterizem promoção pessoal. Ou que não albergue o chamamento das pessoas para participarem de ações governamentais desenvolvida em proveito destas, como campanhas de vacinação e de outras formas de prevenção de doenças, por exemplo.

\subsection{Publicidade Proibida}

São formas de publicidade proibida, nos termos do art. 37 , § $1^{\circ}$, da vigente Constituição Federal, todas aquelas que não tiverem caracteres educativo, informativo ou de orientação social, bem como a propaganda de autoridade ou servidor público, como tal entendida a publicidade que conterem nomes, símbolos ou imagens que caracterizam promoção pessoal.

A qualificação feita pela referência ao caráter informativo certamente não pode ser entendida tomando-se tal palavra em seu sentido literal e isoladamente. Toda e qualquer publicidade tem caráter informativo. A qualificação da espécie, assim, seria inteiramente inócua. Não seria uma qualificação específica porque o caráter informativo é próprio do gênero. A referência a ele para qualificar a espécie há de ser entendida, portanto, como exigência de caráter simplesmente informativo, vale dizer, publicidade sem qualquer outra finalidade que não aquela de informar. Publicidade feita com o objetivo apenas informar, e não informar para influir.

Assim, podemos afirmar que o art. 37, § $1^{\circ}$, da Constituição Federal, proíbe todas as formas publicidade que:

A) impliquem promoção pessoal de autoridade ou servidor público;

B) não tenham caráter educativo ou de orientação social.

C) não tenham caráter exclusivamente informativo.

Importante é observarmos que o fato de ter caráter educativo ou de orientação social não torna lícita e, portanto, permitida a publicidade promocional. Se puder ser caracterizada como forma de promoção pessoal de autoridade ou servidor público a publicidade é proibida, ainda que tenha caráter educativo ou de orientação social.

\subsection{Publicidade Permitida}

A publicidade é um princípio constitucional inerente ao Estado Democrático de Direito, porque neste, como ensina Celso Antônio, o poder emana do povo e 
assim não se pode esconder dos administrados "assuntos que a todos interessam, e muito menos em relação aos sujeitos individualmente afetados por alguma medida." Assim, tem-se de entender que a publicidade permitida - e mais que isto, constitucionalmente determinada - é apenas a que se faça no interesse do povo e não no interesse dos governantes.

A publicidade permitida, portanto, é apenas aquela destinada a permitir aos administrados o controle da atividade administrativa, e a defesa de seus direitos individuais e sociais. Em outras palavras, a publicidade permitida é somente aquela:

A) determinada pela lei para viabilizar o controle da atividade administrativa e a defesa de direitos individuais ou sociais; e

B) que tem caráter educativo ou de orientação social

Mas é importante que se entenda que o ter caráter educativo ou de orientação social não quer dizer apenas veicular, no meio de diversas informações que se destinam apenas a promover a pessoa do governante, pequena mensagem que pode ser considerada educativa. O que torna a publicidade permitida é o ter caráter exclusivamente educativo ou de orientação social.

\subsection{Distinção Essencial Entre Publicidade e Propaganda}

Sabido que publicidade é o gênero e propaganda é uma espécie de publicidade, podemos dizer que essa espécie identifica-se pela finalidade. Enquanto a publicidade tem por fim apenas tornar conhecido o fato divulgado, a propaganda tem por fim fazer isto com o propósito de influir no íntimo das pessoas às quais se dirige, não necessariamente para que comprem um bem ou um serviço, mas para que adotem certo comportamento. ${ }^{3}$

É publicidade, em sentido estrito, aquela que tem caráter simplesmente informativo. Aquela cujo objetivo é apenas o de tornar público aquilo que informa. Que não põe em questão a finalidade para a qual se torna algo público porque a finalidade é apenas a de tornar público, isto é, dar conhecimento aos interessados.

A publicidade, em sentido amplo, inclui a propaganda. Espécie de publicidade que se caracteriza pela finalidade com a qual algo é tornado público. Finalidade que consiste em influir nas condutas de seus destinatários.

A distinção apoiada no critério da finalidade de influir nas condutas de seus destinatários, todavia, é insuficiente para nos permitir separar o que está autorizado do que está proibido pelo art. 37, § $1^{\circ}$, da vigente Constituição Federal. Em princípio, a publicidade autorizada é aquela de caráter simplesmente informativo,

3 Teodoro González Ballesteros. Diccionario Jurídico para Periodistas, Editorial Centro de Estúdios RamónAreces, Madrid, 1998, págs. 669/670. 
sem a finalidade de influir na conduta das pessoas às quais é destinada. A publicidade pura e simples, ou publicidade em sentido estrito. Ocorre que também está autorizada a publicidade com caráter educativo e de orientação social. E mesmo quanto à publicidade em sentido estrito convêm o estabelecimento de critério para se identificar essa espécie de publicidade, evitando-se desta forma que se faça propagando a pretexto de fazer publicidade em sentido estrito.

\subsection{Critérios Práticos de Distinção}

Regra geral para caracterização da publicidade é a desnecessidade de trabalho técnico de elaboração da mensagem divulgada. Divulga-se simplesmente o fato, sem qualquer preocupação de influenciar as pessoas. A publicidade alcança o seu objetivo pelo fato de dar conhecimento ao público da mensagem divulgada. Por isto mesmo não se faz necessária nenhuma habilidade técnica de quem prepara a matéria a ser divulgada. A publicidade apenas torna público o fato. Não importa saber qual será a consequiência que vai produzir na mente das pessoas.

Mas, como também é permitida a publicidade de caráter educativo e de orientação social, esse critério é insuficiente. Necessita-se de algo para distinguir a publicidade destinada simplesmente a dar conhecimento, daquela destinada a educar e a orientar a população. Um critério capaz de ajudar nessa distinção reside no tempo e no autor do fato divulgado. Se a mensagem divulga fato situado no passado que tem como autor o governo, é propaganda: foi feito isto e aquilo. Se a divulgação apenas conclama para um fato futuro que há de ser realizado pelo cidadão ou pela sociedade, anunciando o que a população deve fazer, é publicidade permitida.

Seja como for, sempre existirão mentes prodigiosas prontas para apontar caminhos vários no sentido de burlar a lei na busca da realização dos interesses pessoas dos poderosos que se encontram no exercício do poder. Por isto mesmo a lei deve ser o mais objetiva possível. Deve estabelecer regras que, na medida do possível, resistam às investidas dos poderosos. Para tanto devemos pensar em regras capazes de colocar a serviço de sua preservação algumas forças que de outro modo poderiam estar atuando em sentido contrário.

\subsection{Publicidade Como Serviço Público}

Temos de considerar que a denominada comunicação de massa é um serviço público. Certo que "a publicação de veículo impresso de comunicação independe de licença de autoridade" ${ }^{4}$, e isto nos leva a concluir que o jornal impresso, ou

\footnotetext{
${ }^{4}$ Constituição Federal de 1988, art. 220, § $6^{\circ}$.
} 
jornal no sentido tradicional da palavra, já não é um serviço público. Mas o rádio e a televisão constituem serviço público porque a Constituição estabelece que "o serviço de radiodifusão sonora e de sons e imagens, observado o princípio da complementaridade dos sistemas privado, público e estatal”, depende de concessão do Poder Executivo federal. ${ }^{5}$

Sendo assim, nada impede que ao concessionário do serviço de radiodifusão sonora e de sons e imagens seja imputado o ônus de fazer, sem qualquer pagamento, a publicidade de tudo quanto o governo deva divulgar. Isto fará com que, sem interesse na divulgação, as empresas concessionárias desse serviço ajudem a controlar a publicidade governamental evitando-se assim o abuso dos governantes.

\section{Terceirização Nos Serviços Públicos 3.1. A Onda do Neoliberalismo}

Com a onda do neoliberalismo que se espalha no mundo, passou-se no Brasil a adotar a terceirização da mão de obra nos serviços públicos. Na atividade privada a terceirização pode ser vantajosa. Com ela se busca a vantagem decorrente da especialização. O empresário livra-se do trata com as questões trabalhistas e previdenciárias. Embora assuma o ônus, porque no preço dos serviços que contrata está ele incluído, livra-se da necessidade de lidar com empregados.

Nos serviços públicos, porém, a terceirização é simplesmente desastrosa. É uma porta escancarada para a corrupção, porque torna praticamente impossível o controle do superfaturamento, além de outras formas de fraude que estão disseminadas em todo o País. Há pouco vimos nos jornais locais notícia a respeito de Prefeitura do interior do nosso Estado, dando conta de suspeita de irregularidades em contratos de prestação de serviços. Pequena amostra do que está acontecendo no Brasil inteiro, nos âmbitos federal, estadual e municipal. De ponta a ponta reina a corrupção com aparência de legalidade que lhe empresta a malsinada terceirização.

\subsection{Burla À Exigência de Concurso Público}

Além disto a terceirização de mão de obra nos serviços públicos é uma forma de burla à exigência de concurso público, que assegura oportunidade de ingresso nos serviços públicos a todos os brasileiros pelo critério do mérito pessoal., é uma das maiores conquistas da cidadania brasileira.

${ }^{5}$ Constituição Federal de 1988, art. 223. 
A vigente Constituição Federal diz que:

“os cargos, empregos e funções públicas são acessíveis aos brasileiros que preencham os requisitos estabelecidos em lei, assim como aos estrangeiros, na forma da lei.” E para fazer efetiva essa promessa diz também que "a investidura em cargo ou emprego público depende de aprovação prévia em concurso público de provas ou de provas e títulos, de acordo com a natureza e a complexidade do cargo ou emprego, na forma prevista em lei, ressalvadas as nomeações para cargos em comissão declarado em lei de livre nomeação e exoneração.”6

Os interessados em burlar esses preceitos constitucionais têm trabalhado com a distinção entre atividade fim e atividade meio. Sustentam que as atividades meio podem ser desempenhadas por pessoas que não fazem parte do serviço público. Empregados de empresas privadas que prestam serviços aos órgãos públicos. Os denominados "terceirizados".

A burla é evidente. A norma constitucional não distingue entre atividade fim e atividade meio. Nada justifica a contratação de empresas prestadoras de serviços, ou locadoras de mão de obra, para o desempenho de atividades meio em órgãos públicos.

\subsection{Burla ao Controle da Opinião Pública}

Não faz muito tempo observava-se um forte controle da opinião pública sobre o uso de automóveis oficiais. Os famosos carros "chapas brancas". Automóveis com placas oficiais, brancas ou pretas (de bronze) estacionados nas proximidades de restaurantes, ou de colégios, eram fotografados e objeto de publicidade nos jornais, apontando o abuso na utilização desses veículos que estivessem levando autoridades para restaurantes ou seus filhos para a escola.

Já não se houve mais falar nos “chapas brancas”, ou pretas. Mas o problema do abuso na utilização de automóveis por parte de autoridades continua. Só que disfarçado. Fora do controle da opinião pública.

Realmente, as autoridades atualmente preferem automóveis alugados. O serviço de transporte dessas autoridades é objeto de terceirização. O gasto do governo aumentou, mas o abuso está fora do controle da opinião pública.

${ }^{6}$ Constituição Federal de 1988, art. 37, incisos I e II. 


\subsection{InCREMENTo Na ConcentraçÃo de RENDA}

Os que defendem a terceirização nos serviços públicos geralmente argumentam com a acomodação do servidor público que, cheio de direitos, não se dá ao trabalho. Ganha muito e trabalha pouco. Daí decorreria a ineficiência dos serviços públicos.

O argumento é aparentemente consistente. Mas só aparentemente. Embora em alguns casos realmente exista acomodação do servidor público, essa acomodação pode ser evitada por outros meios, inclusive com a mudança da legislação, se for o caso. Aliás, a prática nos tem mostrado que a terceirização não elimina o problema, além de criar outros, como certa irresponsabilidade de terceirizado que não se sente comprometido com o serviço exatamente porque não tem com ele laços permanentes. Nem seu emprego é melhor do que um outro que poderá arranjar se demitido.

Por outro lado, entre os males da terceirização temos o aumento de oportunidades para a prática de corrupção, a dificuldade no controle das contas públicas e o significativo aumento na concentração de renda no País. Enquanto o gasto com a remuneração de servidores públicos direciona a renda para camadas economicamente mais modestas, a terceirização permite que as empresas explorem os trabalhadores, pagando a estes salários os menores que o mercado permite, de sorte que o gasto com a terceirização termina por carrear as maiores somas para o bolso do empresário na forma de lucro.

\section{\ Considerações Finais}

Invocando a doutrina de Norberto Bobbio, o Senador Marco Maciel, em artigo sobre "Reformas Políticas" (Diário do Nordeste, Fortaleza, 25 de junho de 2006) adverte que não adianta tentarmos mudar os homens porque o importante é fortalecer as instituições. E na verdade mudar governantes não resolve. Renova nossas esperanças mas termina em decepção. Importante é fortalecermos nossas instituições, tornando-as menos vulneráveis.

Proibir a propaganda governamental é fortalecer nossas instituições, evitando-se a aplicação de recursos públicos no interesse pessoal de governantes. Os gastos com propaganda são, além disto, um instrumento de corrupção na medida em que contribuem para calar os órgãos de comunicação de massa, evitando que estes exerçam o seu importante papel na sociedade democrática.

Atribuir as atividades do Estado a seus servidores, titulares de cargos acessíveis a todos os cidadãos mediante concurso público, é outra forma de fortalecer nossas instituições. Na verdade a terceirização nos serviços públicos é uma porta escancarada para a corrupção, além de amesquinhar uma das maiores conquistas da cidadania brasileira que é a exigência de concurso para o ingresso no Serviço Público. 
A contratação de empresas pelos órgãos públicos deve ficar restrita à execução de atividades eventuais por natureza. Não se justifica a criação de cargo público de pedreiro, servente, pintor, porque o órgão público precisa reformar sua sede. Deve contratar com empresa privada a prestação do serviço. Em se tratando, porém, de atividade permanente, devem estas ser desempenhadas por servidores públicos, admitidos mediante concurso, pois somente assim estará sendo obedecido o comando constitucional.

Considerando-se que o Brasil está entre os primeiros lugares no mundo na concentração de renda, o fato de ser a terceirização nos serviços públicos um PPinstrumento que a realiza já é o bastante para preconizarmos a sua extinção. 